\title{
The evaluation of digital panoramic radiographs taken for implant dentistry in the daily practice
}

\section{Jun-Beom Park}

DDS, MSD, PhD Department of Pharmaceutical Sciences, College of Pharmacy, University of Michigan, Ann Arbor, MI, USA

Correspondence:

Department of Pharmaceutical Sciences

College of Pharmacy,

University of Michigan

428 Church Street,

Ann Arbor, MI, 48109 USA

jbassoonis@yahoo.co.kr

Received: 17/08/2009

Accepted: $24 / 12 / 2009$

Park JB. The evaluation of digital panoramic radiographs taken for implant dentistry in the daily practice. Med Oral Patol Oral Cir Bucal. 2010 Jul 1;15 (4):e663-6.

http://www.medicinaoral.com/medoralfree01/v15i4/medoralv15i4p663.pdf

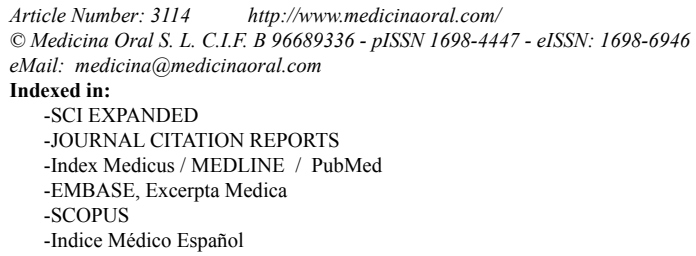

\begin{abstract}
Objectives: This study was conducted $1 /$ to find out the effects of anatomical sites and implant types on the magnification and $2 /$ to evaluate the inter-observer variability on the evaluation using the digital panoramas taken at daily practices.

Study design: Panoramic radiographs from 156 patients treated with implants were evaluated by three observers. The length was measured on the lateral aspect of the implant in 1:1 mode using image measurement program and the percent magnification was calculated. The inter-observer correlation coefficient was measured to express inter-observer variability using reliability analysis-scale.

Results: The average magnification factor in the panoramic radiograph was $126.8 \%$ in the vertical plane. Location within the anatomic arch showed different magnification by a minimum of $119.4 \%$ to a maximum of $130.8 \%$. The measurements among three examiners were well correlated showing correlation coefficient of 0.81 . The differences between one side and the contralateral side were evaluated and it was shown that the differences were observed only in maxillary anterior and maxillary premolar regions. Additionally, the external non-submerged group had the highest magnification value.

Conclusions: It can be concluded that digital panoramic radiographs showed sufficient accuracy and good interexaminer agreement. The radiographic magnification of implant length may be influenced by anatomical sites and implant types.
\end{abstract}

Key words: Magnification, radiography, panoramic, implant, digital. 


\section{Introduction}

There are more diagnostic tools available than ever before to assist the clinician in the pre-surgical planning of dental implants. Many techniques have been suggested to evaluate the bone quality, bone quantity and anatomical limitations $(1,2)$. Radiographic examination is considered a prerequisite for preoperative planning in implant treatment and panoramic radiographs have been used widely in dentistry, especially in implant dentistry due to their availability and accessibility (3). In the digital system, the film-based image is replaced by a two-dimensional array of pixels. There are several studies investigating on the accuracy and precision of digital panoramic radiographs and most of the reports concluded that the digital panoramic system was equally as useful as conventional film-based panoramic radiographs $(4,5)$. However, it was also reported that panoramic radiography had limitations of distortion, superimposition with variability in inter-examiner agreement (6).

This study was conducted (1) to find out the effects of anatomical sites and implant types on the magnification and (2) to evaluate the inter-observer variability on the evaluation using the digital panoramas taken at daily practices.

\section{Materials and Methods}

Dental records and panoramic radiographs of patients treated with implant-supported prosthesis at Armed Forces Capital Hospital, Gyenggi-do, Korea from October 2003 through April 2005 were evaluated. 156 patients treated with the implants were included in the study. The total number of implants included in this study was 354 . Patient ages ranged from 19 to 58 years (mean age, $42.7 \pm 12.1$ ). The three different types of implants (external submerged type (US II ${ }^{\circledR}$, Osstem, Seoul, Korea), internal submerged type (Implantium ${ }^{\circledR}$, Dentium, Seoul, Korea) and internal non-submerged type $\left(\mathrm{SS} \mathrm{II}^{\circledR}\right.$, Osstem) were used. Panoramic radiographs were evaluated by three observers (one periodontist and two hospital corpsmen).

In a clinical setting, the patient's head was placed in the $\mathrm{x}$-ray apparatus using bite block supports. The sagittal plane was set at the vertical beam of the light-beam localizer. In this report, the technicians were calibrated for the technique prior to the study to reduce positional errors. All radiographs in this study were taken with digital panoramic system $\left(\right.$ Cranex ${ }^{\circledR}$, Soredex, Helsinki, Finland). According to the manufacturer's manual, 65 $\mathrm{kV}$ and $6 \mathrm{~mA}$ were set and the exposure time was 16 s. The equipment had CCD-sensor with active sensor surface of $147.5 \times 6.1 \mathrm{~mm}^{2}$ and provided a pixel size of $96 \mu \mathrm{m}$. The signals were acquired at a bit depth of 12 bit (=4096 gray levels). The length was measured on the lateral aspect of the implant in 1:1 mode using image measurement program $\left(\mathrm{m}-\mathrm{view} \mathrm{w}^{\mathrm{TM}}\right.$, Marotech, Seoul, Korea). The percent magnification was established using the following formula: [radiographic magnification=(implant length measured on radiograph)/(actual implant length)*100\%]. The average magnification factor in the panoramic radiograph was calculated in the vertical plane. The differences between one side and the contralateral side and the effect of implant length on magnification were evaluated. Separate analyses were made for three different implant systems (external submerged type, internal submerged type and internal non-submerged type).

The inter-observer correlation coefficient was measured to express inter-observer variability using reliability analysis-scale (alpha). Two-way analysis of variance (ANOVA) post hoc (Tukey HSD) was used to test for differences between groups and the level of significance value considered was 0.05 . Statistical analysis was performed using Statistical Package for the Social Sciences (version 16.0.2 for Windows; SPSS, Chicago, IL, USA).

\section{Results}

The average magnification factor in the panoramic radiograph was $126.8 \%$ in the vertical plane. Lower anterior region showed the lowest magnification and the lower premolar area generated the highest value (Table 1). The differences between one side from the contralateral side were evaluated and it was shown that the differences were observed only seen maxillary anterior and maxillary premolar area (Table 2). The effect of implant length on magnification was evaluated and it was shown that mean magnification for different implant length ranged from 124.2 to $128.6 \%$ with lowest value from the group with implants having longest length. Magnifications for three different groups of external submerged, internal submerged and external non-submerged group were $121.6 \pm 9.5 \%, 126.3 \pm 9.3 \%$, and $130.6 \pm 6.1 \%$, respectively. It was seen that external submerged implant type had the lowest magnification and external non-submerged group had the highest value.

The inter-observer agreement for the measurement of radiographic magnification showed good reliability with reliability coefficient alpha of 0.81 .

\section{Discussion}

This study was performed to find out the effects of anatomical sites and implant types on the magnification using the digital panoramas taken at daily practices. Comparisons of film-based and digital radiography were performed previously and visualization of anatomical structures was reported to be worse in digital images than in film images (7). However, this study showed that the digital panoramic radiographs showed sufficient accuracy with a minimum of $119.4 \%$ and a maximum of $130.8 \%$, which supports the finding from conventional 
Table 1. Radiographic magnification of implants by anatomic location.

\begin{tabular}{cccc}
\hline Location & Mean & \multicolumn{2}{l}{ SD } \\
\hline Maxilla & & & \\
Anterior & 122.4 & 10.6 & \\
Premolar & 124.8 & 8.8 & \\
Molar & 128.8 & 6.1 & \\
\hline Mandible & & & \\
Anterior & 119.4 & 8.5 & \\
Premolar & 130.8 & 5.5 & \\
Molar & 127.3 & 7.1 & \\
\hline Total & 126.8 & 8.1 & \\
\hline
\end{tabular}

*: This showed significant differences between two groups ( $\mathrm{p}<0.05)$.SD: Standard Deviation.

Table 2. Comparison between one side from the contralateral side.

\begin{tabular}{|c|c|c|c|c|c|}
\hline Location & Mean & SD & Mean & SD & Sig \\
\hline Maxilla & Right & & Left & & \\
\hline Anterior & 125.0 & 9.2 & 113.5 & 10.2 & $*$ \\
\hline Premolar & 127.1 & 5.6 & 111.2 & 12.4 & $*$ \\
\hline Molar & 129.2 & 4.3 & 128.4 & 7.6 & \\
\hline Mandible & Right & & Left & & \\
\hline Anterior & 121.6 & 6.1 & 117.9 & 9.7 & \\
\hline Premolar & 131.2 & 5.8 & 129.8 & 4.4 & \\
\hline Molar & 128.1 & 7.0 & 126.6 & 7.2 & \\
\hline
\end{tabular}

*: Significant differences were seen between left and right sides $(\mathrm{p}<0.05)$. SD: Standard Deviation.

radiograph showing minimum of 120 and a maximum of $132 \%(8)$. It is usually expected that an average magnification of $125 \%$ is seen in panoramic images (9). The results from a dry skull showed that the vertical enlargement ratio varies between 121 and 129\% (10).

Differences in magnification of implant length existed among the different location. Mandibular premolar region had the highest value of $130.8 \%$, which was $3 \%$ higher than previous reported data (8).

Several studies have considered positioning errors as significant factor that could influence radiographic magnification $(11,12)$. It was seen that only maxillary anterior and maxillary premolar region showed significant differences from each sides. Even though, upper incisors have the advantages of being single rooted and do not usually affected by overlap, they have the disadvantages of being more readily subject to positioning errors and superimposition of the cervical spine (6). It is also reported that mandibular molars are usually better seen than other teeth on a panoramic radiograph and positioning errors have a less profound effect on these teeth. The calibration procedure of using bite block supports and vertical beam may have reduced the positional errors.

The effect of implant length on magnification ranged from 124.3 to $128.6 \%$ with highest value from the group with implants having longest length and it can be assumed that the magnification occurs relatively evenly throughout the regions.

There are only a few reports evaluating the effect of the different implant systems (13). It was reported that only small differences were found between the different implant systems and the Straumann system seemed less affected by the calibration methods. Unlike this, internal submerged implant type showed the closest values $(126 \%)$ to the average magnification factor of $125 \%$. The external non-submerged type had the highest value and this may be due to the fact that this type of implant has the transmucosal compartment attached to the implant fixture and this may have lead to overestimated values. The value alpha was used to determine the inter-observer agreement. An alpha of 0.7 is widely accepted to be the cut off point to be acceptable and values between 0.7 and 0.9 are considered good (14). Thus, it can be assumed that the inter-observer agreement using digital panoramas showed good reliability.

The prospective clinical study using the panoramic radiographs to evaluate the preoperative planning of 
posterior mandibular implants showed that panoramic radiographs appeared to be sufficient to evaluate available bone height before insertion of posterior mandibular implants when a safety margin of at least $2 \mathrm{~mm}$ above the mandibular canal is respected (15).

Taken together, it can be concluded that panoramic radiographs showed sufficient accuracy with good interexaminer agreement. The radiographic magnification of implant length may be influenced by anatomical sites and implant types.

\section{References}

1. Dula K, Mini R, van der Stelt PF, Buser D. The radiographic assessment of implant patients: decision-making criteria. Int $\mathrm{J}$ Oral Maxillofac Implants. 2001;16:80-9.

2. Misch CE. Density of bone: effect on treatment plans, surgical approach, healing, and progressive boen loading. Int J Oral Implantol. 1990;6:23-31.

3. McDavid WD, Dove SB, Welander U, Tronje G. Dimensional reproduction in direct digital rotational panoramic radiography. Oral Surg Oral Med Oral Pathol. 1993;75:523-7.

4. Schulze R, Krummenauer F, Schalldach F, d'Hoedt B. Precision and accuracy of measurements in digital panoramic radiography. Dentomaxillofac Radiol. 2000;29:52-6.

5. Benediktsdottir IS, Hintze H, Petersen JK, Wenzel A. Accuracy of digital and film panoramic radiographs for assessment of position and morphology of mandibular third molars and prevalence of dental anomalies and pathologies. Dentomaxillofac Radiol. 2003;32:10915.

6. Carmichael FA, Hirschmann PN, Scaife B, Sheard L, Mackenzie A. A comparison of the diagnostic utility of two image receptors for panoramic radiography. Dentomaxillofac Radiol. 2000;29:57-60.

7. Molander B, Gröndahl HG, Ekestubbe A. Quality of film-based and digital panoramic radiography. Dentomaxillofac Radiol. 2004;33:32-6

8. Choi YG, Kim YK, Eckert SE, Shim CH. Cross-sectional study of the factors that influence radiographic magnification of implant diameter and length. Int J Oral Maxillofac Implants. 2004;19:594-6. 9. Reddy MS, Mayfield-Donahoo T, Vanderven FJ, Jeffcoat MK. A comparison of the diagnostic advantages of panoramic radiography and computed tomography scanning for placement of root form dental implants. Clin Oral Implants Res. 1994;5:229-38.

10. Gomez-Roman G, Lukas D, Beniashvili R, Schulte W. Area-dependent enlargement ratios of panoramic tomography on orthograde patient positioning and its significance for implant dentistry. Int $\mathrm{J}$ Oral Maxillofac Implants. 1999;14:248-57.

11. Yeo DK, Freer TJ, Brockhurst PJ. Distortions in panoramic radiographs. Aust Orthod J. 2002;18:92-8.

12. Schulze R, Schalldach F, d'Hoedt B. [Effect of positioning errors on magnification factors in the mandible in digital panorama imaging]. Mund Kiefer Gesichtschir. 2000;4:164-70.

13. Schropp L, Stavropoulos A, Gotfredsen E, Wenzel A. Calibration of radiographs by a reference metal ball affects preoperative selection of implant size. Clin Oral Investig. 2009;13:375-81.

14. Custers RJ, Creemers LB, Verbout AJ, van Rijen MH, Dhert WJ, Saris DB. Reliability, reproducibility and variability of the traditional Histologic/Histochemical Grading System vs the new OARSI Osteoarthritis Cartilage Histopathology Assessment System. Osteoarthritis Cartilage. 2007;15:1241-8.

15. Vazquez L, Saulacic N, Belser U, Bernard JP. Efficacy of panoramic radiographs in the preoperative planning of posterior mandibular implants: a prospective clinical study of 1527 consecutively treated patients. Clin Oral Implants Res. 2008;19:81-5.

\section{Acknowledgement}

The author claims to have no financial interest in any company or any of the products mentioned in this article. The author would like to thank Lim HS and Yoo KB for for their invaluable assistance for the gathering and analyzing the data for this study. 